\title{
A single dose of allopregnanolone affects rat ovarian morphology and steroidogenesis
}

\author{
Laura Tatiana Pelegrina ${ }^{1}$, Antonella Rosario Ramona Cáceres ${ }^{2}$, Fernando Alfredo Giuliani ${ }^{1}$, \\ Joana Antonella Asensio ${ }^{1}$, Fernanda Parborell ${ }^{3}$ and Myriam Raquel Laconi ${ }^{1}$ \\ 'Laboratorio de Fisiopatología ovárica y Neurobiología, Instituto de Medicina y Biología Experimental de Cuyo \\ (IMBECU-CONICET), Inbiomed-UM, Mendoza, Argentina, ²Laboratorio de Fisiopatología ovárica y Neurobiología, \\ Instituto de Medicina y Biología Experimental de Cuyo (IMBECU-CONICET), Inbiomed-UM, Universidad Juan \\ Agustín Maza, Mendoza, Argentina, and ${ }^{3}$ Laboratorio de Fisiopatología del ovario. Instituto de Biología y Medicina \\ Experimental (IByME-CONICET), Buenos Aires, Argentina
}

Correspondence should be addressed to M R Laconi; Email: mlaconi@yahoo.com

\begin{abstract}
Allopregnanolone, a progesterone metabolite, is one of the best characterized neurosteroids. In a dose that mimics serum levels during stress, allopregnanolone inhibits sexual receptivity and ovulation and induces a decrease in luteinizing hormone levels. The aim of this work was to examine the effect of an intracerebroventricular administration of allopregnanolone on ovarian morphophysiology; serum and tissue levels of progesterone and estrogen; and enzymatic activity of $3 \beta$-hydroxysteroid dehydrogenase, $20 \alpha$-hydroxysteroid dehydrogenase and $3 \alpha$-hydroxysteroid oxido-reductase in the ovary and in the medial basal hypothalamus on the morning of estrus. Ovarian morphology was analyzed under light microscopy. The hormone assays were performed by radioimmunoassay. The enzymatic activities were measured by spectrophotometric analysis. The morphometric analysis revealed that, in allopregnanolone-treated animals, the number of secondary and Graafian follicles was decreased, whereas that of atretic follicles and cysts was significantly increased. Some cysts showed luteinized unruptured follicles. There were no differences in the number of tertiary follicles or corpora lutea in comparison with the corresponding control groups. In allopregnanolone-treated animals,

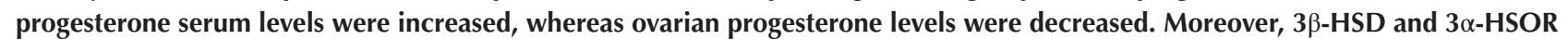
enzymatic activities were increased in the medial basal hypothalamus, whereas ovarian levels were decreased. The enzyme $20 \alpha$-hydroxysteroid dehydrogenase showed the opposite profile. The results of this study showed that allopregnanolone interferes on ovarian steroidogenesis and ovarian morphophysiology in rats, providing a clear evidence for the role of this neurosteroid in the control of reproductive function under stress situations.

Free Spanish abstract: A Spanish translation of this abstract is freely available at http://www.reproduction-online.org/ content/153/1/75/suppl/DC1.

Reproduction (2017) 153 75-83
\end{abstract}

\section{Introduction}

Steroids are synthesized by the brain de novo from cholesterol or from an in situ metabolism of peripheral hormone precursors. As a whole, these steroids are known as 'neurosteroids' (Robel \& Baulieu 1994, Baulieu 1997, Melcangi \& Panzica 2006, Melcangi et al. 2011). Neurosteroids are synthesized, stored and released in the central nervous system (CNS) and in the peripheral nervous system independently of classical steroidogenic glands, such as gonads and adrenals (Robel \& Baulieu 1985, Corpéchot et al. 1993, Baulieu 1997, Melcangi \& Panzica 2006). These neurosteroids include pregnenolone, progesterone (Pg) and allopregnanolone (ALLO). In particular, ALLO, also called $3 \alpha$-hydroxy-5 $\alpha$-pregnan-20-one or $3 \alpha-5 \alpha$-tetrahydroprogesterone, is a metabolite of $\mathrm{Pg}$
(Majewska et al. 1986) and is synthesized in astrocytes (Micevych et al. 2003) and oligodendrocytes (MensahNyagan et al. 1999). ALLO synthesis implies the conversion of Pg to pregnenolone by $3 \beta$-hydroxysteroid dehydrogenase $(3 \beta-\mathrm{HSD})$ and the reduction of this steroid by $3 \alpha$-hydroxysteroid oxido-reductase

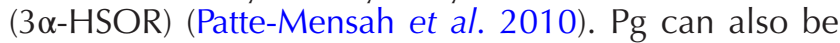
metabolized by 20 $\alpha$-hydroxysteroid dehydrogenase (20 $\alpha$-HSD) (Clementi et al. 2004). These enzymes are present in different regions, including the hypothalamus (Guennoun et al. 1995, Vidal et al. 2000) and the ovary (Vega Orozco et al. 2012). Micevych and Sinchak (2008) mentioned that neurosteroids are not isolated from peripheral steroid sources. Mutual interactions modulate their levels in the brain and periphery. Moreover, to provide a reservoir of steroids, circulating hormonal steroids modulate the site-specific synthesis 
of neurosteroids and their cognate receptors. This dual regulation of neurosteroidogenesis and post-synaptic receptor expression has profound implications for neurosteroid function. Interactions of peripheral steroids with neurosteroid synthesis are involved in regulating reproduction in the hypothalamus. The contribution from the brain to the pool of ALLO measured in serum is minimal (in the order of $\mathrm{nM}$ ), whereas the peripheral contribution of the sum of adrenal and ovarian production is in the order of $\mu \mathrm{M}$ (Purdy et al. 1990, 1991, Micevych \& Sinchak 2008).

ALLO is a positive allosteric modulator of the $\mathrm{GABA}_{\mathrm{A}}$ receptor and its effects are similar to those of benzodiazepines and include sedative and anticonvulsant activities (Kokate et al. 1999, Laconi et al. 2001). Its action on the $\mathrm{GABA}_{\mathrm{A}}$ receptor is related to its neuro-protective, neuro-modulatory and antigonadotropic properties (Purdy et al. 1991, Concas et al. 1996). The potency of ALLO in increasing GABAactivated $\mathrm{Cl}^{-}$currents is comparable to high-potency benzodiazepine. As in $\mathrm{Cl}^{-}$flux studies (Morrow et al. 1987), low nanomolar concentrations of ALLO increase GABA-activated $\mathrm{Cl}^{-}$currents, whereas higher concentrations, in the low micromolar range, directly activate a bicuculline-sensitive $\mathrm{Cl}^{-}$current.

The affinity of ALLO for $\mathrm{GABA}_{A}$ receptors is comparable to that of benzodiazepines, and ALLO is one of the most potent $G_{A B A}$ receptor ligands. ALLO actions are mediated by synaptic and extra-synaptic receptors. ALLO interacts with synaptic $\mathrm{GABA}_{\mathrm{A}}$ receptors to produce phasic inhibition via specific bindings (Paul \& Purdy 1992).

Pg and ALLO have been studied in clinical trials of psychiatric disorders such as depression, anxiety, premenstrual irritability and menopausal syndrome as well as in neurodegenerative diseases such as Parkinson or Alzheimer and post-traumatic neuronal repair (Bicíková \& Hampl 2007).

Previously, we reported that ALLO increases GnRH release through the glutamatergic system and NMDA receptors (Giuliani et al. 2011). Other authors reported that ALLO, in different strains of GT1 neurons, might either stimulate or have no effect on the release of $\mathrm{GnRH}$ (Sleiter et al. 2009). Moreover, we have reported that i.c.v administration of ALLO induces an increase in endogenous dopamine concentration with a decrease in the dopamine/dopac turnover rate in the medial basal hypothalamus $(\mathrm{MBH})$, indicating an increase in dopamine metabolism. This action is mediated by the $\mathrm{GABA}_{\mathrm{A}}$ receptor (Laconi \& Cabrera 2002). In addition, ALLO is able to reduce LH serum levels and anxiety levels and to inhibit lordosis in female rats (Laconi et al. 2001, Laconi \& Cabrera 2002, Pelegrina et al. 2015). Moreover, Sleiter and coworkers (2009) found that Pg inhibits $\mathrm{GnRH}$ release through an action on membrane Pg receptors, but more evidence is needed to clarify the role of ALLO in GnRH release (Giuliani et al. 2011).
Circulating levels of ALLO are usually according with Pg levels but stress or pathological situations could alter both ALLO and Pg levels (Purdy et al. 1991, Genazzani et al. 1995). Stress is one of the main factors that alter ALLO circulating levels (Purdy et al. 1991), which could alter the reproductive axis. Bäckström and coworkers (2011) have shown that neurosteroid concentrations are variable, especially those acting on the $\mathrm{GABA}_{\mathrm{A}}$ receptor and can induce mood changes in women. These changes become more apparent during the premenstrual phase, when the levels of $\mathrm{Pg}$ and ALLO are the highest. Studies in our laboratory have shown that the anxiolytic effect of ALLO in female rats is associated with their hormonal status (Laconi et al. 2001, 2007, Laconi \& Cabrera 2002). Recently, we studied the effect of central administration of ALLO doses that mimic the circulating levels during stress and found that ALLO inhibits LH and the ovulation rate and increases prolactin serum levels. In addition, ALLO inhibits corpus luteum apoptosis (Laconi et al. 2012) and the loss of ovulation may be due to its effect over the hypothalamic-pituitary axis.

$\mathrm{Pg}$ stimulates luteal cells to secrete more $\mathrm{Pg}$ in a paracrine manner, protecting corpora lutea from cell death (Stocco et al. 2007). The functional and structural luteal development of luteal cells is controlled by the action of several luteotropic hormones secreted by the pituitary gland, the endometrium and the placenta, in the case of pregnancy. Among the best-known luteotropic hormones are PRL and LH (Niswender et al. 2000). ALLO could also be a candidate to control the previously mentioned process (Laconi et al. 2012).

Ovarian cysts are an important cause of subfertility in mammals, as well as of the polycystic ovarian syndrome and the luteinized unruptured follicle (LUF) syndrome in women (Summaria et al. 1998, Ali 2015). Cysts can be subdivided into follicular and luteal cysts, which could be different forms of the same disorder. Follicular cysts are dynamic structures that develop when one or more follicles fail to ovulate (Vanholder et al. 2006). Some kinds of cysts do not interfere with the estrous or menstrual cycle (Douthwaite \& Dobson 2000, Noble et al. 2000) and can appear in the absence of clear clinical signs, such as LUFs, which are formed from Graafian follicles in the absence of oocyte expulsion in women with normal menstrual cycles and animal models (Killick \& Elstein 1987, Van de Lagemaat et al. 2011). During the follicular phase, granulosa cells acquire luteinization potential, which is suppressed until ovulation (Williams \& Erickson 2012). In the LUFs, the process of ovulation is dysregulated. Failure of ovulation due to the luteinization of follicles under the action of $\mathrm{LH}$ is one of the main causes of infertility in women (Summaria et al. 1998, Qublan et al. 2006).

Considering our previous findings, the aim of this work was to determine the effect of a dose of ALLO $(6 \mu \mathrm{M}$ i.c.v.) on the ovarian morphophysiology, Pg and 
$17 \beta$-estradiol serum and ovarian levels, and $3 \beta-H S D$, $3 \alpha-$ HSOR and $20 \alpha-$ HSD enzymatic activities in the ovary and $\mathrm{MBH}$.

\section{Materials and methods}

\section{Animals}

Adult female Sprague-Dawley rats (60-90 days old; body weight 200-250g) bred in our laboratory were used. Animals were housed at room temperature $\left(22 \pm 2^{\circ} \mathrm{C}\right)$ with a $12 \mathrm{~h}$ light: $12 \mathrm{~h}$ darkness photoperiod in an air-conditioned environment. Food and water were available ad libitum (standard rat chow Cargil, Córdoba, Argentina). Only animals with two consecutive 4-5-day cycles were used for the experiment. The stages of the estrous cycle were determined daily by vaginal cytology.

\section{Experimental design}

In the morning of proestrous, rats were injected i.c.v. with ALLO $(6 \mu \mathrm{M}, 1 \mu \mathrm{L}$ injection volume, for $60 \mathrm{~s})$. Control animals were injected with KREBS solution (as vehicle) containing propylene glycol at concentrations equivalent to those used in the experimental groups. The chosen dose of ALLO mimics the serum levels during stress in rats (Purdy et al. 1991) and is the same dose used in our previous reports (Laconi et al. 2001, 2002, 2012, Giuliani et al. 2013, Pelegrina et al. 2015). Six rats per group were used in each experiment, which was performed only once. In the morning of estrous (09:00 h), vaginal smears were analyzed. Then, the rats were killed by decapitation. The brains were rapidly removed and cooled on ice and the $\mathrm{MBH}$ explants dissected out. The anterior border of each block of tissue was made by a coronal cut just anterior to the entry point of the optic chiasm and the posterior border by a coronal cut just behind the pituitary stalk. The lateral limits were the hypothalamic fissures and the in-depth limit was the sub-thalamic sulcus. The $\mathrm{MBH}$ of each animal was labeled for subsequent measurement of enzymatic activity.

Serum samples were collected after blood centrifugation and stored at $-30^{\circ} \mathrm{C}$ until used for radioimmunoassay (RIA). The ovaries were removed and cleaned free of fat, and oocytes were collected by the puncture of the ampulla and counted under a light microscope. The right ovary was frozen to measure Pg and enzymatic activity, whereas the left ovary was fixed in Bouin solution (Biopur Diagnostics) for subsequent microscopic analysis. All protocols were previously approved by the Experimental Animal Committee of the Universidad Nacional de Cuyo, Argentina (CICUAL No 141021) and conducted according to the National Institutes of Health Guide for the Care and Use of Laboratory Animals of the National Research Council (National Academies, U.S.A., 8th Edition, 2011).

\section{Drugs}

Allopregnanolone (ALLO) (3 $\alpha$-hydroxy-5 $\alpha$-pregnan-20-one) (Sigma Chemical Co.), Penicillin G Benzathine (Richet,
Argentina), Ketamine HCL (Holliday-Scott S.A, Buenos Aires, Argentina) and Xylazine (Koning Laboratories, Buenos Aires, Argentina) were used for experimental and surgical

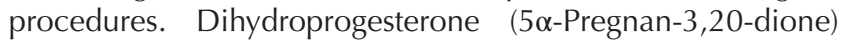
(Sigma Aldrich), Pregnenolone (3 $\beta$-hydroxy-5-pregnen-20-one) (Sigma Aldrich), NAD+ ( $\beta$-Nicotinamide adenine dinucleotide hydrate) and NADPH ( $\beta$-Nicotinamide adenine dinucleotide phosphate) (all from Sigma Aldrich) were used for enzymatic activity determination. ALLO was prepared as described in our previous papers (Laconi et al. 2001, 2012). Stocks of ALLO were initially dissolved in propylene glycol to a concentration of $0.6 \mathrm{mM}$. The dose of ALLO used in the experiment $(6 \mu \mathrm{M})$ was obtained by dilutions in Krebs Ringer Bicarbonate glucose (KRBG) buffer at $\mathrm{pH} 7.4$, to make negligible the final amount of propylene glycol. Control animals were injected with KRBG buffer at $\mathrm{pH} 7.4$ as vehicle. KRBG preparation contained propylene glycol in a concentration equivalent to that used in the experimental groups.

\section{Determination of the estrous cycle and the ovulation rate}

The estrous cycle stage was determined daily (07:00-09:00 h) using vaginal smears observed with a light microscope. The ovulation rate was determined on the morning of estrous after the rats were killed to confirm our previous results (Laconi et al. 2012). After killing, the ovary was placed on a petri dish, moistened slightly and the ampulla was gently punctured. Then, oocytes were removed and counted under a light microscope. ADVANCE $\backslash \mathrm{d} 1$

\section{Surgical procedures}

A stainless-steel cannula was stereotaxically inserted into the right lateral ventricle in rats anesthetized with an intraperitoneal injection of Ketamine $\mathrm{HCL}(80 \mathrm{mg} / \mathrm{kg})$ and xylazine $(4 \mathrm{mg} / \mathrm{kg})$. A stainless-steel needle was placed into the guide cannula and connected by a silicone catheter to a Hamilton microliter syringe. After inoculation, the injection cannula was maintained for an additional minute to avoid reflux. The following coordinates from bregma were used, in accordance with Paxinos and Watson's Atlas (2009), AP: $0.4 \mathrm{~mm}, \mathrm{~L}:-1.5 \mathrm{~mm}$ and DV: $-4 \mathrm{~mm}$. At the end of the surgery, the cannula was sealed with a stainless-steel wire to protect it from obstruction. To prevent infections, each animal received a subcutaneous injection of $0.2 \mathrm{~mL}$ of Penicillin G Benzathine (1,200,000 IU; $1 \mathrm{IU}=0.6 \mu \mathrm{g} ; 72 \mathrm{mg} / \mathrm{rat})$. After surgery, animals were housed singly in Plexiglas cages and maintained undisturbed for a week for recovery. At the end of the experiments, the location of the guide cannula into the lateral ventricle was confirmed by the injection of blue ink. Only animals with confirmed microinjection into the right lateral ventricle were included in the study.

On the morning of proestrous $(09: 00 \mathrm{~h})$, the experimental group ( $n=6$ rats) received a single i.c.v. injection of ALLO $(6 \mu \mathrm{M})$ and the vehicle group received an i.c.v. injection of KREBS solution. The total volume of ALLO or vehicle injected was $1 \mu \mathrm{L}$ for $60 \mathrm{~s}$. 


\section{Ovarian morphology}

The left ovaries from both experimental groups were removed and immediately fixed in Bouin solution (Biopur) for $12 \mathrm{~h}$, dehydrated in ethanol series, cleared in xylene and embedded in paraffin. Histological sections were made for staining with hematoxylin and eosin (Merck). Ovaries were cut in serial sections at $5 \mu \mathrm{m}$ on a rotary microtome, mounted on slides at $50-\mu \mathrm{m}$ intervals to prevent counting the same structure twice and examined under a light microscope (Zeiss). From each ovary, the number of secondary (SF), tertiary (TF), Graafian (GF) and atretic (AtF) follicles as well as corpora lutea (CL) and cysts (C), including LUFs, were examined under a light microscope (Zeiss). The follicles were classified in accordance with Williams and Erickson (2012): SFs have multiple layers of granulosa cells around the oocyte and a theca layer; TFs contain a small cavity or 'antrum' filled with follicular fluid; in GF, the cavity occupies most of the total follicular volume and the cumulus appears; AtFs were those with more than 10 pycnotic nuclei per follicle, which also had a degenerate oocyte and precocious antrum formation or both (Banka \& Erickson 1985, Sadrkhanloo et al. 1987). The CLs of each individual were counted and classified in new and old (previous cycle) according to Westwood (2008), as follows: New CL: easily found during estrous. They are generally small, but defined, with basophilic cell cytoplasm, central fluidfilled cavity and no fibrous tissue (Fig. 1C); Old CL: might be found throughout the whole cycle. They can present more cytoplasmic vacuoles indicative of active steroidogenesis and fibrous tissue proliferation in the central cavity (Fig. 1D).

Follicular cysts were defined as follicles with or without oocytes that contain a large antral cavity and a thin granulosa layer. LUFs were defined as structures with an oocyte surrounded by luteal and granulosa cells, with neovascularization (Wang et al. 2008, Fernandois et al. 2012). The number of these different ovarian structures was determined in six ovarian sections from each ovary ( $n=6$ ovaries/group) and expressed as mean \pm S.E.M. The mean diameter of TF, GF and CL was recorded using ImageJ software.

\section{Radioimmunoassay for progesterone and estradiol determination in serum and ovarian tissue}

Trunk blood was collected and centrifuged at $402 \mathbf{g}$ for $15 \mathrm{~min}$ (Beckman TJ-6RS). The serum obtained was kept frozen $\left(-30^{\circ} \mathrm{C}\right)$ until hormone assays were run. RIA was performed using a commercially obtained kit (New England Nuclear Products, Boston, MA, USA) and used to measure progesterone concentrations in serum and ovaries. In both cases, Pg was extracted according to Sánchez-Criado and coworkers (1992). The sensitivity of the assay was $0.02 \mathrm{ng} / \mathrm{mL}$, and inter- and intraassay coefficients of variation were $5 \%$ and $6 \%$ respectively, for serum measures. 17 $\beta$-Estradiol (E2) concentration in serum was determined by RIA using a commercial kit (Radim, Pomezia, Italy) based on competition between antigens labeled with iodine 125 (radioactive conjugate) and non-labeled antigens (calibrator sample) for specific binding sites in antiserum-coated tubes. After incubation, all unbound material was removed and radioactivity was measured. Uncoated tubes were prepared for measurements of total activity (T) and non-specific binding (NSB). Tubes coated with rabbit antibody against E2 were prepared for measurements in the zero calibrator (Bo), calibrators 1-6, control serum and samples as follows. First, $100 \mu \mathrm{L}$ of Bo was added to the NSB tube and $100 \mu \mathrm{L}$ of each additional calibrator as well as the control serum and samples was pipetted into the corresponding tube. Next, $500 \mu \mathrm{L}$ of the radioactive conjugate was pipetted into all the tubes, whose contents were then mixed by vortex. After incubation for $3 \mathrm{~h}$ at $37^{\circ} \mathrm{C}$, the contents were carefully aspirated by pump from all tubes except the uncoated $\mathrm{T}$ tube. The radioactivity in the tubes was measured with a $\gamma$-counter. The sensitivity of the assay was $2 \mathrm{pg}$. The intra-assay coefficient of variation (CV) was 3\%. In the case of the ovarian Pg measures, the concentration was expressed as $\mathrm{ng} / \mathrm{mg}$ ovary/mL, and assay

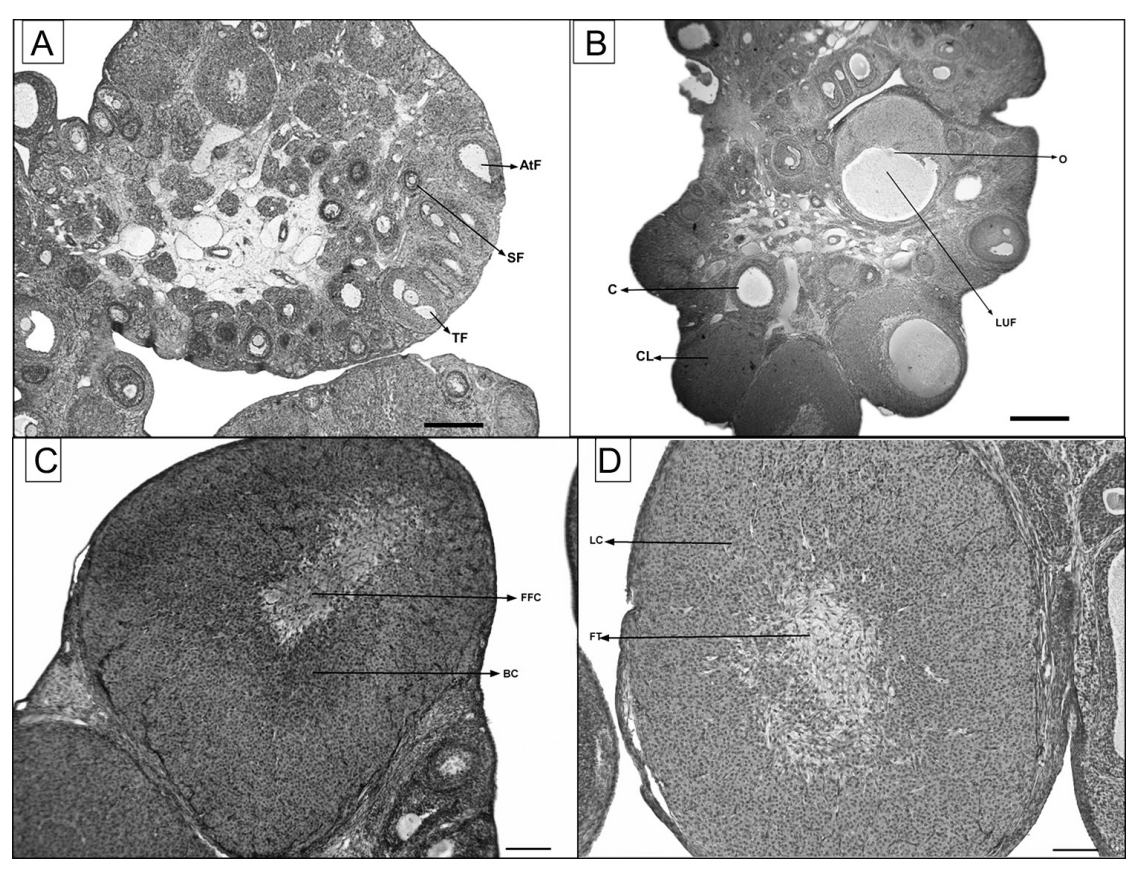

Figure 1 Top panel: Light micrographs of whole ovaries from rats after treatment with vehicle (A) or ALLO (B). Inset: Luteinized unruptured follicle (LUF) containing an oocyte $(\mathrm{O})$. A secondary follicle (SF), a tertiary follicle (TF), corpora lutea $(\mathrm{CL})$, an atretic follicle (AtF) and a cyst $(\mathrm{C})$ are also shown. Bottom panel: Representative micrographs of a new corpus luteum $(\mathrm{C})$ with basophilic cells $(\mathrm{BC})$ and a fluid-filled cavity (FFC); and an old corpus luteum (D) with central fibrous tissue formation (FT) and luteinized cells (LC). Scale bars in A and B represent $200 \mu \mathrm{m}$, in C and D $100 \mu \mathrm{m}$. 
Table 1 Morphometric features of ovarian follicles in ovaries after treatment with ALLO or vehicle in female rats.

\begin{tabular}{lccc}
\hline Structures & Control $(n=6)$ & ALLO $(n=6)$ & P value \\
\hline Secondary follicles $(\mathrm{n})$ & $3.94 \pm 0.56$ & $2.77 \pm 0.33$ & $<0.05$ \\
Tertiary follicles $(\mathrm{n})$ & $7.5 \pm 0.96$ & $6.2 \pm 0.95$ & $\mathrm{~ns}$ \\
Graafian follicles $(\mathrm{n})$ & $5.1 \pm 0.45$ & $3 \pm 0.66$ & $<0.01$ \\
Atretic follicles $(\mathrm{n})$ & $2.75 \pm 1.1$ & $4.77 \pm 0.9$ & $<.001$ \\
Corpora lutea $(\mathrm{n})$ & $7.65 \pm 2.20$ & $6.35 \pm 1.1$ & $\mathrm{~ns}$ \\
New CL $(\mathrm{n})$ & $3.55 \pm 1.16$ & $5.60 \pm 0.85$ & $<.76 \pm 2.26$ \\
Old CL $(\mathrm{n})$ & $3.25 \pm 2$ & $6 \pm 1.33$ & $<0.001$ \\
Cysts and LUFs $(\mathrm{n})$ & $2 \pm 0.55$ & $432.53 \pm 104.28$ & $<0.001$ \\
Diameter of tertiary follicles $(\mu \mathrm{m})$ & $428.87 \pm 102.49$ & $603.62 \pm 65.12$ & $\mathrm{~ns}$ \\
Diameter of Graafian follicles $(\mu \mathrm{m})$ & $650.85 \pm 97.62$ & $\mathrm{~ns}$ & $\mathrm{~ns}$ \\
Diameter of corpora lutea $(\mu \mathrm{m})$ & $758 \pm 65.01$ & $836.3 \pm 82.3$ & \\
\hline
\end{tabular}

Values expressed as mean \pm S.E.M., ns, not significant.

$\mathrm{CL}$, corpora lutea; LUF, luteinized unruptured follicles.

sensitivity was less than $5 \mathrm{ng} \mathrm{Pg} / \mathrm{mL}$. The inter- and intra-assay CVs were less than $10.0 \%$. For the sake of comparison, some previously published data regarding Pg serum levels are shown together with Pg ovarian levels.

\section{Spectrophotometric analysis of enzymatic activity (ovary and $\mathrm{MBH}$ )}

The right ovary from each animal was used both for Pg determination by RIA (see previous paragraph) and for enzymatic activity determination. First, the ovaries were homogenized in buffer Tris- $\mathrm{Hcl}$, and then an aliquot was taken for determination of enzyme activities. The remaining aliquot was used for RIA determination. The activities of $3 \beta$-HSD, $3 \alpha-$ HSOR and $20 \alpha-H S D$ were measured as described by Kawano and coworkers (1988) and Giuliani and coworkers (2013), with slight modifications (Tellería \& Deis 1994). The method of Lowry and coworkers (1951) was used for protein determination using bovine serum albumin (BSA) as standard. The ovaries and $\mathrm{MBH}$ were homogenized in $0.7 \mathrm{~mL}$ of $0.1 \mathrm{M}$ Tris- $\mathrm{HCl}$ and $1 \mathrm{mM}$ EDTA buffer $(\mathrm{pH} 8)$ at $0^{\circ} \mathrm{C}$ with a glass homogenizer. The homogenates were centrifuged at 30,000 rpm for 60 min, using a Beckman L T40.2 ultracentrifuge. The supernatants were used for determining $20 \alpha-H S D$ activity. The precipitates were re-homogenized with $0.25 \mathrm{M}$ sucrose and then centrifuged at $3000 \mathrm{rpm}$ for $5 \mathrm{~min}$. The supernatants obtained were used as the enzyme solution to determine $3 \beta$-HSD activity. Then, to start the assays, the substrate for the reaction of $3 \alpha-\mathrm{HSOR}$, pregnenolone, was added to the reaction mix. The latter contained glycine- $\mathrm{NaOH}$ $(\mathrm{pH}=9.4), \mathrm{BSA}, \mathrm{NAD}+$ and a fraction of the enzyme solution. The enzymatic activities were assayed spectrophotometrically using a Zeltec spectrophometer. The assay of each enzyme measured the reduction of NAD+ or the oxidation rate of $\mathrm{NADPH}$ at $340 \mathrm{~nm}$ respectively (Kawano et al. 1988, Takahashi et al. 1995, Escudero et al. 2012) as an increase in absorbance in $1 \mathrm{~min}$ at $37^{\circ} \mathrm{C}$. A fraction of the enzymatic solution was reserved for protein quantification. The values of enzymatic activity were expressed as $\mathrm{U} / \mathrm{mg}$ protein/min.

\section{Data analysis}

Data were expressed as the mean \pm S.E.M. Statistical analysis was performed using the unpaired Student's $t$ test. Values of
$P<0.05$ were considered significant. Data were statistically analyzed using Prism v 5.0.

\section{Results}

\section{Estrous cycle and ovulation}

ALLO administration at proestrous caused a significant decrease in the ovulation rate. The percentage of inhibition was of $75 \%$, whereas the administration of vehicle had no effect (data not shown). Interestingly, the estrous cycle was not modified in any of the experimental groups.

\section{Ovarian morphology}

The mean numbers of follicles and CL in the ALLOtreated and control groups are shown in Table 1. In the ALLO-treated group, the number of SF and GF was lower than that in the control group $(P<0.05$ and $P<0.01$ respectively). In contrast, the number of
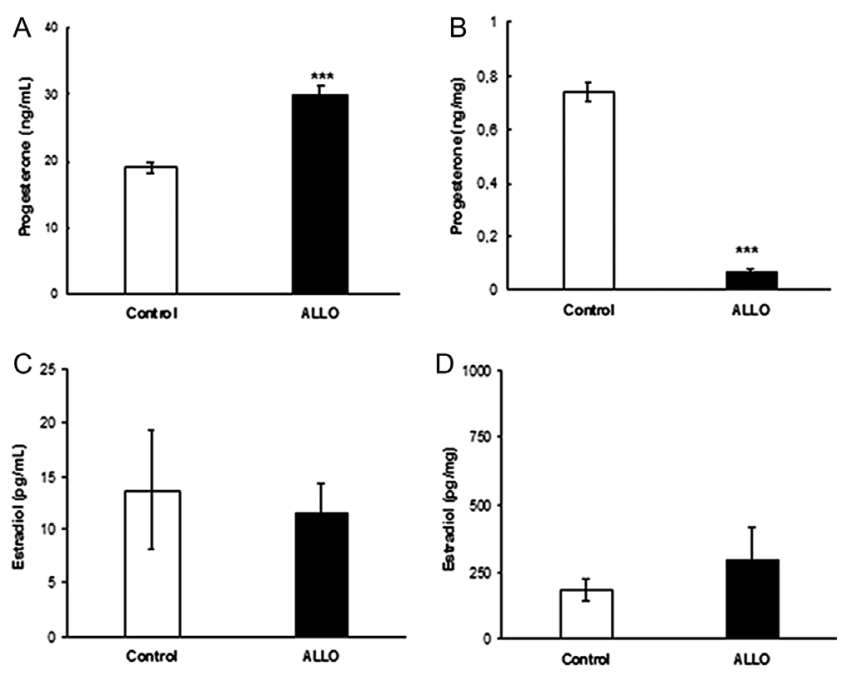

Figure 2 Radioimmunoassay of progesterone (top panel) and estrogen (bottom panel); serum levels $(\mathrm{ng} / \mathrm{mL}$ ) (A and C) and ovarian tissue levels (ng/mg) (B and D). Allopregnanolone (ALLO). Bars represent the mean \pm S.E.M. $\left(n=6 ;{ }^{* * *} P<0.001\right)$. 
follicular cysts and LUFs was increased in the ALLOtreated group $(P<0.001)$. No significant differences were found in the number of TF and CL between both groups. ALLO increased the number of old $\mathrm{CL}$ and decreased the number of new $\mathrm{CL}$, compared to the untreated group. There were no significant differences between the diameters of TF, GF and CL between the ALLO-treated and control animals (Table 1). Figure 1 (upper panel) shows representative photomicrographs of a whole control ovary (A) and a whole ALLO-treated ovary (B), which display a LUF with retained oocyte, a large antrum and intense vascularization. Figure 1 (lower panel) shows photomicrographs of new (Fig. 1C) and old corpora lutea (Fig. 1D).

\section{Progesterone and estrogen levels}

ALLO administration induced a significant increase in Pg serum levels with respect to the control group
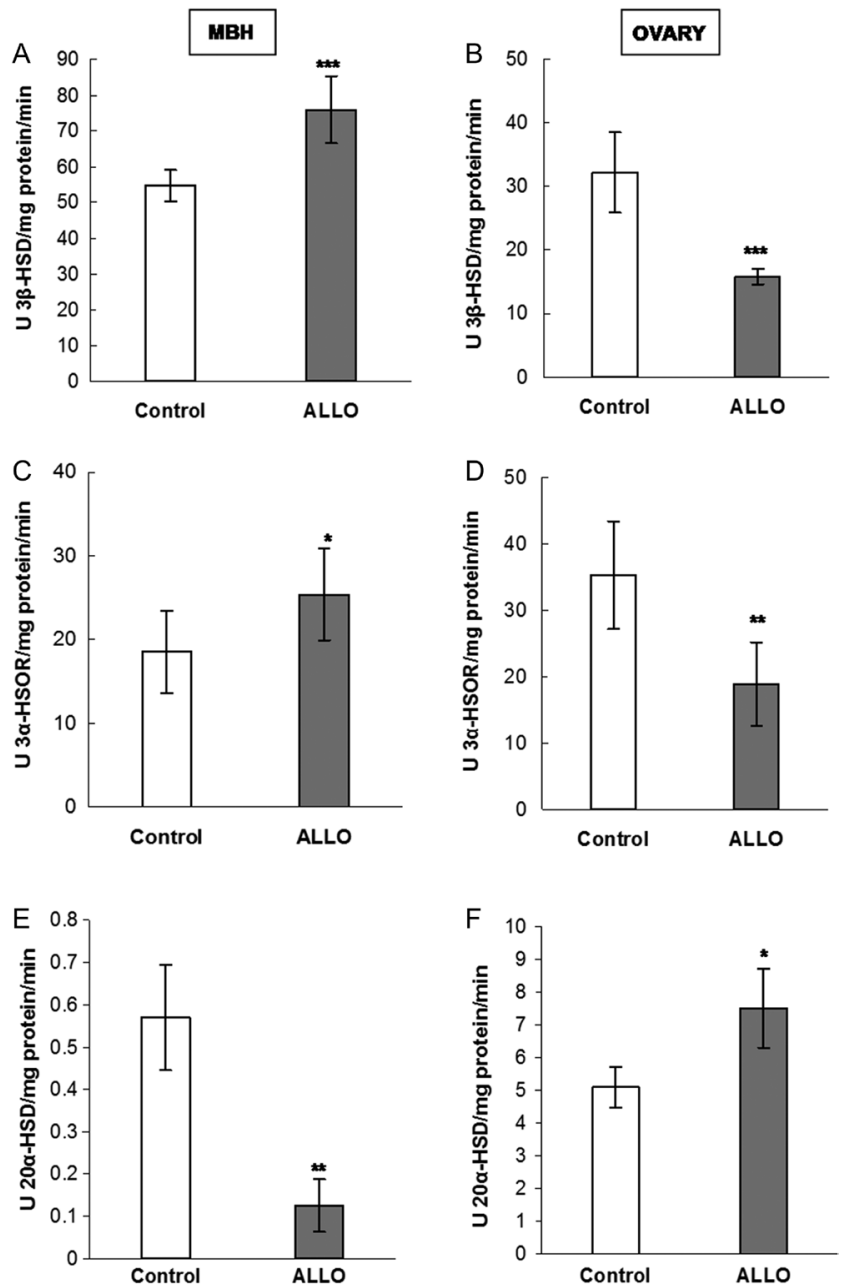

Figure 3 Spectrophotometric analysis of ALLO effect over $3 \beta-H S D$ (A and B), $3 \alpha-$ HSOR (C and D) and $20 \alpha-H S D$ (E and F) enzymatic activities in the medial basal hypothalamus (MBH left panel) and in the ovary (right panel) of estrous rats. Bars represent the mean \pm S.E.M. $\left(n=6 ; * P<0.05,{ }^{* *} P<0.01\right.$ and $\left.{ }^{* * *} P<0.001\right)$.
$(P<0.001$, Fig. 2A). However, the opposite results were found in the ovaries, where Pg levels were lower than those of the control group $(P<0.001$, Fig. 2B). The administration of ALLO did not alter serum or ovarian estradiol levels when compared with the control group (Fig. 2C and D).

\section{$3 \beta-H S D, 3 \alpha-H S O R$ and $20 \alpha-H S D$ enzymatic activity}

The $3 \beta-H S D$ activity in MBH of ALLO-treated animals was significantly higher than that of the control group $(P<0.05$, Fig. 3A). In the ovaries, the opposite results $(P<0.05$, Fig. 3B) were found: $3 \beta-\mathrm{HSD}$ was lower in the ALLO-treated groups than that in the control group. The same changes in the enzymatic activity of $3 \alpha-\mathrm{HSOR}$ were observed in both $\mathrm{MBH}$ and ovarian samples $(P<0.05$, Fig. 3C and D). Finally, ALLO administration induced a decrease in the activity of $20 \alpha-H S D$ in the $\mathrm{MBH}$ and an increase in the activity of $20 \alpha-\mathrm{HSD}$ in the ovary $(P<0.05$, Fig. 3E and F).

\section{Discussion}

Ovulation is one of the main female reproductive events. It is a consequence of sequential steps that begin early in life with the formation of primordial follicles and then, during the fertile period with cyclic follicular development. This process is controlled by the hypothalamic-pituitary-ovarian axis, which is accompanied by an increased sympathetic tone. ALLO plays a determinant role in the regulation of the reproductive function in female rats. We have previously shown that ALLO modifies the ovulation pattern, acting at the level of the dopaminergic, GABAergic and glutamatergic systems (Laconi et al. 2001, 2012, Laconi \& Cabrera 2002, Giuliani et al. 2013). Based on these previous findings, this study was designed to analyze the putative effect of a single dose of ALLO i.c.v. over morphometric parameters and ovarian and hypothalamic steroidogenesis.

We confirmed that the i.c.v. administration of ALLO inhibited ovulation, a mechanism controlled primarily by the pituitary LH. ALLO administration did not alter the estrous cycle. These results are in agreement with those of Genazzani and coworkers (1995), who had already found that after the administration of anti-ALLO serum, the anovulatory effect of the neurosteroid was reversed.

In the present study, we observed that ALLO affects the process of follicle maturation. In the ALLO-treated group, the number of SF and GF was significantly lower than that in the control group, whereas their diameter was not affected. On the other hand, ALLO increased the number of AtF. As shown in one of our previous works (Laconi et al. 2012), ALLO interferes with gonadotropin release. At a concentration in the order of $\mu \mathrm{M}, \mathrm{ALLO}$ 
is able to decrease LH serum levels, whereas at a concentration in the order of $\mathrm{nM}$, it is able to increase GnRH levels (Giuliani et al. 2011). These findings support the idea that ALLO alters gonadal steroidogenesis and thus disrupts follicular development. ALLO may also alter the balance between survival and death factors in follicular cells, leading to the atresia of developing follicles.

The ovulatory process, which involves the breakdown of the theca layers, which in turn allows the release of the oocyte, is dependent on $\mathrm{Pg}$ and the regulation of proteolytic activity. In addition, this process is dependent on the pre-ovulatory $\mathrm{LH}$ surge that induces the secretion of follicular Pg (Gaytán et al. 2002). Our findings suggest that ALLO inhibits ovulation by decreasing the ovarian levels of $\mathrm{Pg}$, an effect that seems to be mediated by the inhibition of $3 \beta$-HSD activity and by an increase in $20 \alpha-$ HSD activity.

Previously, we found that ALLO affects luteal regression through the inhibition of apoptosis (Laconi et al. 2012). In this study, we observed that in animals injected with ALLO, the mean number of $C L$ and their diameters had no differences with respect to the control group. Although the difference of the total number of $\mathrm{CL}$ remained statistically not significant, there was a difference in the number of new and old CL between the ALLO-treated group and the control group. The decrease in the number of new CL could be a consequence of the inhibition of ovulation or of the increase in the number of atretic and cystic follicles. The increase in the number of old CL could be associated with a decrease in the apoptotic process in the CL (Laconi et al. 2012).

The increase in 20 $\alpha$-HSD activity and the decrease in $3 \beta-H S D$ activity observed in the present study, together with the decline in the number of new $\mathrm{CL}$, would be the cause for the decrease in ovarian Pg levels. Luteal regression initiates with a decline in the biosynthesis of Pg (Clementi et al. 2004), which is then followed by the activation of the catabolism of Pg by $20 \alpha-\mathrm{HSD}$, an established marker for luteal regression.

Moreover, as is well known, follicle maturation is a process regulated by gonadotropins, hormones and local growth factors (Fortune et al. 2004). Follicular growth and oocyte maturation are dependent primarily on FSH and LH (Canipari et al. 2012). Mattheij and Swarts (1995) linked a deficiency in the secretion of LH in the period before ovulation with the formation of LUFs. Therefore, the central effect of ALLO over the reproductive function may be due to decreased LH levels, which affect folliculogenesis and thus inhibit ovulation. This process would be involved in the formation of ovarian cysts and, in particular, LUFs. This is in agreement with that found by Vanholder and coworkers (2006) who mentioned that low LH levels lead to the formation of cystic structures, which do not interfere with the normal ovarian cycle in cows. Women with LUFs have a normal menstrual cycle without ovulation (Summaria et al. 1998). The same situation occurred in our experimental model, where the rats presented a normal four- to five-day cycle, with regular vaginal smears, with a significant reduction of the ovulation, even though follicular cysts and LUF were increased.

In our model, ALLO probably affects the selectionrecruitment of dominant follicles to ovulate, preventing them to reach the GF state, thus leading to the formation of cystic structures. This idea reinforces our hypothesis about the importance of this neurosteroid in the reproductive function, in particular in the functionality of ovarian structures.

On the other hand, we found that ALLO increased serum Pg levels and decreased ovarian Pg levels, but did not affect serum or ovarian estrogen levels. All these results suggest that ALLO acts both at central (CNS) and peripheral levels (adrenal and ovarian levels) (Micevych \& Sinchak 2011).

In this study, we measured the ovarian and $\mathrm{MBH}$ enzymatic activities of $3 \beta-\mathrm{HSD}, 3 \alpha-\mathrm{HSOR}$ and $20 \alpha-H S D$, which mediate the synthesis and metabolism of $\mathrm{Pg}$ and ALLO respectively. We found that the activities of both $3 \beta-$ HSD and $3 \alpha-$ HSOR had the same profile. They were increased at $\mathrm{MBH}$ and decreased in ovarian tissue, suggesting a relationship between the central and ovarian effect of ALLO. However, 20 $\alpha$-HSD activity followed the opposite profile: in the $\mathrm{MBH}$, it might regulate the availability of locally produced Pg from $\mathrm{Pg}$ receptors, and thus, control the influence of Pg over neuronal activity; in the ovary, it plays a relevant role in the induction of luteolysis (Pelletier et al. 2004, Stocco et al. 2007).

De Rensis and Scaramuzzi (2003) have shown the effect of heat stress over female fertility. The decrease in fertility is associated with an increased body temperature that alters ovarian function and oocyte health (Hansen 2007). Wolfenson and coworkers $(1997,2000)$ have reported that stress can alter follicular development, lead to the the formation of suboptimal $\mathrm{CL}$ and low Pg concentration and reduce steroid hormone production. Similarly, we reported that a concentration of ALLO that mimics stress levels also has a deleterious effect on GF, leading to the formation of cystic and luteinized structures. ALLO, at stress level concentrations, may generate a cascade of effects from the hypothalamus and pituitary gland to the ovary, impairing the whole equation of female fertility. It alters luteal function and follicular development, reduces ovarian Pg concentration, decreases the enzymatic activities of $3 \beta-$ HSD and $3 \alpha-$ HSOR and increases $20 \alpha-$ HSD activity.

In conclusion, ALLO alters key enzymes of its own synthesis and generates a special microenvironment, causing alterations in steroidogenesis, perhaps responsible for the morphological changes in follicles and the development of cystic structures, reinforcing the idea that ALLO is a potent modulator of female reproductive function. 
More studies are needed to ascertain if ALLO actions could affect the ovarian tissue directly. We are currently studying the effect of an ALLO intra-bursal injection and determining ALLO serum levels.

\section{Declaration of interest}

The authors declare that there is no conflict of interest that could be perceived as prejudicing the impartiality of the research reported.

\section{Funding}

CONICET (PIP 11220100100126), Universidad de Mendoza (Project 133/10) and Universidad Juan Agustin Maza (2015-2017), Argentina, supported this study.

\section{Acknowledgements}

This study was financially supported by grants of National Research Council of Argentina (CONICET PIP 11220100100126), by from Universidad de Mendoza 133/2014 and Universidad Maza. Drs Myriam Laconi and Fernanda Parborell are established investigators at the National Research Council of Argentina (CONICET). Dr Laura T Pelegrina is a fellow from CONICET.

\section{References}

Ali AT 2015 Polycystic ovary syndrome and metabolic syndrome. Ceska Gynekologie 80 279-289.

Bäckström T, Haage D, Löfgren M, Johansson IM, Strömberg J, Nyberg S, Andréen L, Ossewaarde L, van Wingen GA, Turkmen S et al. 2011 Paradoxical effects of GABA-A modulators may explain sex steroid induced negative mood symptoms in some persons. Neuroscience 191 46-54. (doi:10.1016/j.neuroscience.2011.03.061)

Banka CL \& Erickson GF 1985 Gonadotropin-releasing hormone induces classical meiotic maturation in subpopulations of atretic preantral follicles. Endocrinology 117 1500-1507. (doi:10.1210/endo-117-41500)

Baulieu EE 1997 Neurosteroids: of the nervous system, by the nervous system, for the nervous system. Recent Progress in Hormone Research $521-32$.

Bicíková M \& Hampl R 2007 Neurosteroids and their function. Casopís Lékar̆ů Českých 146 223-226.

Canipari R, Cellini V \& Cecconi S 2012 The ovary feels fine when paracrine and autocrine networks cooperate with gonadotropins in the regulation of folliculogenesis. Current Pharmaceutical Design 18 245-255. (doi:10.2174/138161212799040411)

Clementi MA, Deis RP \& Telleria CM 2004 Luteal 3beta-hydroxysteroid dehydrogenase and 20alpha-hydroxysteroid dehydrogenase activities in the rat corpus luteum of pseudopregnancy: effect of the deciduoma reaction. Reproductive Biology and Endocrinology 2 22-30. (doi:10.1186/1477-7827-2-22)

Concas A, Mostallino MC, Perra C, Lener R, Roscetti G, Barbaccia ML, Purdy RH \& Biggio G 1996 Functional correlation between allopregnanolone and [35S]-TBPS binding in the brain of rats exposed to isoniazid, pentylenetetrazol or stress. British Journal of Pharmacology 118 839-846. (doi:10.1111/j.1476-5381.1996.tb15476.x)

Corpéchot C, Young J, Calvel M, Wehrey C, Veltz JN, Touyer G, Mouren M, Prasad VV, Banner C, Sjövall J et al. 1993 Neurosteroids: 3 alphahydroxy-5 alpha-pregnan-20-one and its precursors in the brain, plasma, and steroidogenic glands of male and female rats. Endocrinology 133 1003-1009. (doi:10.1210/en.133.3.1003)
De Rensis F \& Scaramuzzi RJ 2003 Heat stress and seasonal effects on reproduction in the dairy cow - a review. Theriogenology $\mathbf{6 0}$ 1139-1151. (doi:10.1016/S0093-691X(03)00126-2)

Douthwaite R \& Dobson H 2000 Comparison of different methods of diagnosis of cystic ovarian disease in cattle and an assessment of its treatment with a progesterone-releasing intravaginal device. Veterinary Record 147 355-359. (doi:10.1136/vr.147.13.355)

Escudero C, Casas S, Giuliani F, Bazzocchini V, García S, Yunes R \& Cabrera R 2012 Allopregnanolone prevents memory impairment: effect on mRNA expression and enzymatic activity of hippocampal 3- $\alpha$ hydroxysteroid oxide-reductase. Brain Research Bulletin 87 280-285. (doi:10.1016/j.brainresbull.2011.11.019)

Fernandois D, Lara HE \& Paredes AH 2012 Blocking of $\beta$-adrenergic receptors during the subfertile period inhibits spontaneous ovarian cyst formation in rats. Hormone and Metabolic Research 44 682-687. (doi:10.1055/s-0032-1304607)

Fortune JE, Rivera GM \& Yang MY 2004 Follicular development: the role of the follicular microenvironment in selection of the dominant follicle. Animal Reproduction Science 82-83 109-126. (doi:10.1016/j. anireprosci.2004.04.031)

Gaytán F, Tarradas E, Bellido C, Morales C \& Sánchez-Criado JE 2002 Prostaglandin $\mathrm{E}(1)$ inhibits abnormal follicle rupture and restores ovulation in indomethacin-treated rats. Biology of Reproduction $\mathbf{6 7}$ 1140-1147. (doi:10.1095/biolreprod67.4.1140)

Genazzani AR, Palumbo MA, de Micheroux AA, Artini PG, Criscuolo M, Ficarra G, Guo AL, Benelli A, Bertolini A, Petraglia F et al. 1995 Evidence for a role for the neurosteroid allopregnanolone in the modulation of reproductive function in female rats. European Journal of Endocrinology 33 375-380. (doi:10.1530/eje.0.1330375)

Giuliani FA, Yunes R, Mohn CE, Laconi M, Rettori V \& Cabrera R 2011 Allopregnanolone induces $\mathrm{LHRH}$ and glutamate release through NMDA receptor modulation. Endocrine 40 21-26. (doi:10.1007/s12020-0119451-8)

Giuliani FA, Escudero C, Casas S, Bazzocchini V, Yunes R, Laconi MR \& Cabrera R 2013 Allopregnanolone and puberty: modulatory effect on glutamate and GABA release and expression of $3 \alpha$-hydroxysteroid oxidoreductase in the hypothalamus of female rats. Neuroscience 243 64-75. (doi:10.1016/j.neuroscience.2013.03.053)

Guennoun R, Fiddes RJ, Gouézou M, Lombès M \& Baulieu EE 1995 A key enzyme in the biosynthesis of neurosteroids, 3 beta-hydroxysteroid dehydrogenase/delta 5-delta 4-isomerase (3 beta-HSD), is expressed in rat brain. Brain Research: Molecular Brain Research 30 287-300. (doi:10.1016/0169-328X(95)00016-L)

Hansen PJ 2007 Exploitation of genetic and physiological determinants of embryonic resistance to elevated temperature to improve embryonic survival in dairy cattle during heat stress. Theriogenology 1 S242-S249. (doi:10.1016/j.theriogenology.2007.04.008)

Kawano T, Okamura H, Tajima C, Fukuma K \& Katabuchi H 1988 Effect of RU 486 on luteal function in the early pregnant rat. Journal of Reproduction and Fertility 83 279-285. (doi:10.1530/jrf.0.0830279)

Killick S \& Elstein M 1987 Pharmacologic production of luteinized unruptured follicles by prostaglandin synthetase inhibitors. Fertility and Sterility 47 773-777. (doi:10.1016/S0015-0282(16)59163-8)

Kokate TG, Juhng KN, Kirkby RD, Llamas J, Yamaguchi S \& Rogawski MA 1999 Convulsant actions of the neurosteroid pregnenolone sulfate in mice. Brain Research 831 119-124. (doi:10.1016/S00068993(99)01287-1)

Laconi MR \& Cabrera RJ 2002 Effect of centrally injected allopregnanolone on sexual receptivity, luteinizing hormone release, hypothalamic dopamine turnover, and release in female rats. Endocrine 17 77-83. (doi:10.1385/ENDO:17:2:077)

Laconi MR, Casteller G, Gargiulo PA, Bregonzio C \& Cabrera RJ 2001 The anxiolytic effect of allopregnanolone is associated with gonadal hormonal status in female rats. European Journal of Pharmacology 417 111-116. (doi:10.1016/S0014-2999(01)00865-2)

Laconi MR, Reggiani PC, Penissi A, Yunes R \& Cabrera RJ 2007 Allopregnanolone modulates striatal dopamingergic activity of rats under different gonadal hormones conditions. Neurological Research 29 622-627. (doi:10.1179/016164107X166281)

Laconi MR, Chavez C, Cavicchia JC, Fóscolo M, Sosa Z, Yunes RF \& Cabrera RJ 2012 Allopregnanolone alters the luteinizing hormone, prolactin, and progesterone serum levels interfering with the regression 
and apoptosis in rat corpus luteum. Hormone and Metabolic Research 44 632-638. (doi:10.1055/s-0032-1314834)

Lowry OH, Rosebrough NJ, Farr AL \& Randall RJ 1951 Protein measurement with the Folin phenol reagent. Journal of Biological Chemistry 193 265-275.

Majewska MD, Harrison NL, Schwartz RD, Barker JL \& Paul SM 1986 Steroid hormone metabolites are barbiturate-like modulators of the GABA receptor. Science 23 1004-1007. (doi:10.1126/science.2422758)

Mattheij JA \& Swarts HJ 1995 Induction of luteinized unruptured follicles in the rat after injection of luteinizing hormone early in prooestrus. European Journal of Endocrinology 132 91-96. (doi:10.1530/ eje.0.1320091)

Melcangi RC \& Panzica GC 2006 Neuroactive steroids: old players in a new game. Neuroscience 138 733-739. (doi:10.1016/j. neuroscience.2005.10.066)

Melcangi RC, Panzica G \& Garcia-Segura LM 2011 Neuroactive steroids: focus on human brain. Neuroscience 191 1-5. (doi:10.1016/j. neuroscience.2011.06.024)

Mensah-Nyagan AG, Do-Rego JL, Beaujean D, Luu-The V, Pelletier G \& Vaudry H 1999 Neurosteroids: expression of steroidogenic enzymes and regulation of steroid biosynthesis in the central nervous system. Pharmacological Reviews 51 63-81.

Micevych P, Sinchak K, Mills RH, Tao L, Lapolt P \& Lu JK 2003 The luteinizing hormone surge is preceded by an estrogen-induced increase of hypothalamic progesterone in ovariectomized and adrenalectomized rats. Neuroendocrinology 78 29-35. (doi:10.1159/000071703)

Micevych P \& Sinchak K 2008 Synthesis and function of hypothalamic neuroprogesterone in reproduction. Endocrinology 149 2739-2742. (doi:10.1210/en.2008-0011)

Micevych P \& Sinchak K 2011 The neurosteroid progesterone underlies estrogen positive feedback of the LH surge. Estrogenic Control of Hypothalamic GnRH Neurons, 48.

Morrow AL, Suzdak PD \& Paul SM 1987 Steroid hormone metabolites potentiate GABA receptor-mediated chloride ion flu with nanomolar potency. European Journal of Pharmacology 142 483-485. (doi:10.1016/0014-2999(87)90094-X)

Niswender GD, Juengel JL, Silva PJ, Rollyson MK \& McIntush EW 2000 Mechanisms controlling the function and life span of the corpus luteum. Physiological Reviews $801-29$.

Noble KM, Tebble JE, Harvey D \& Dobson H 2000 Ultrasonography and hormone profiles of persistent ovarian follicles (cysts) induced with low doses of progesterone in cattle. Journal of Reproduction and Fertility 120 361-366. (doi:10.1530/reprod/120.2.361)

Patte-Mensah C, Meyer L, Schaeffer V \& Mensah-Nyagan AG 2010 Selective regulation of 3 alpha-hydroxysteroid oxido-reductase expression in dorsal root ganglion neurons: a possible mechanism to cope with peripheral nerve injury-induced chronic pain. Pain 150 522-534. (doi:10.1016/j.pain.2010.06.004)

Paul SM \& Purdy RH 1992 Neuroactive steroids. FASEB Journal 6 2311-2322.

Paxinos G \& Watson C 2009 The Rat Brain in Stereotaxic Coordinates. London, UK: Academic Press.

Pelegrina LT, Escudero C, Giuliani FA, García SM, Cabrera RJ \& Laconi MR 2015 Pharmacological effect of one icv dose of allopregnanolone in the female rat: behavioral profile. Brazilian Journal of Biological Sciences 2 39-50.

Pelletier G, Luu-The V, Li S \& Labrie F 2004 Localization of 20alphahydroxysteroid dehydrogenase mRNA in mouse brain by in situ hybridization. Brain Research: Molecular Brain Research 125 143-146. (doi:10.1016/j.molbrainres.2004.02.020)

Purdy RH, Morrow AL, Blinn JR \& Paul SM 1990 Synthesis, metabolism, and pharmacological activity of 3 alpha-hydroxy steroids which potentiate GABA-receptor-mediated chloride ion uptake in rat cerebral cortical synaptoneurosomes. Journal of Medicinal Chemistry 33 1572-1581. (doi:10.1021/jm00168a008)

Purdy RH, Morrow AL, Moore PH \& Paul SM 1991 Stress-induced elevations of $\gamma$-aminobutiric acid type A receptor-active steroids in the rat brain. Neurobiology 10 4553-4557. (doi:10.1073/ pnas.88.10.4553)

Qublan H, Amarin Z, Nawasreh M, Diab F, Malkawi S, Al-Ahmad N \& Balawneh M 2006 Luteinized unruptured follicle syndrome: incidence and recurrence rate in infertile women with unexplained infertility undergoing intrauterine insemination. Human Reproduction $\mathbf{2 1}$ 2110-2113. (doi:10.1093/humrep/del113)

Robel P \& Baulieu EE 1985 Neuro-steroids: 3 $\beta$-hydroxy- $\Delta 5$-derivatives in the rodent brain. Neurochemistry International 7 953-958. (doi:10.1016/0197-0186(85)90143-3)

Robel P \& Baulieu EE 1994 Neurosteroids biosynthesis and function. Trends in Endocrinology and Metabolism 5 1-8. (doi:10.1016/10432760(94)90114-7)

Sadrkhanloo R, Hofeditz C \& Erickson GF 1987 Evidence for widespread atresia in the hypophysectomized estrogen-treated rat. Endocrinology 120 146-155. (doi:10.1210/endo-120-1-146)

Sánchez-Criado JE, Uilenbroek JT \& Karels B 1992 Different effects of the antiprogesterone RU486 on progesterone secretion by the corpus luteum of rats with 4- and 5-day oestrous cycles. Journal of Endocrinology 32 115-122. (doi:10.1677/joe.0.1320115)

Sleiter N, Pang Y, Park C, Horton TH, Dong J, Thomas P \& Levine JE 2009 Progesterone receptor A (PRA) and PRB-independent effects of progesterone on gonadotropin-releasing hormone release. Endocrinology 150 3833-3844. (doi:10.1210/en.2008-0774)

Stocco C, Kwintkiewicz J \& Cai Z 2007 Identification of regulatory elements in the Cyp19 proximal promoter in rat luteal cells. Journal of Molecular Endocrinology 39 211-221. (doi:10.1677/JME-07-0026)

Summaria V, Speca S \& Mirk P 1998 Ovarian factor infertility. Rays 23 709-726.

Takahashi M, Iwata N, Hara S, Mukai T, Takayama M \& Endo T 1995 Cyclic change in 3 alpha-hydroxysteroid dehydrogenase in rat ovary during the estrous cycle. Biology of Reproduction 53 1265-1270. (doi:10.1095/ biolreprod53.6.1265)

Tellería CM \& Deis RP 1994 Effect of RU486 on ovarian progesterone production at proestrus and during pregnancy: a possible dual regulation of the biosynthesis of progesterone. Journal of Reproduction and Fertility 102 379-384. (doi:10.1530/jrf.0.1020379)

van de Lagemaat $R$, van Koppen CJ, Krajnc-Franken MA, Folmer BJ, van Diepen HA, Mulders SM \& Timmers CM 2011 Contraception by induction of luteinized unruptured follicles with short-acting low molecular weight FSH receptor agonists in female animal models. Reproduction 142 893-905. (doi:10.1530/REP-11-0234)

Vanholder T, Opsomer G \& de Kruif A 2006 Aetiology and pathogenesis of cystic ovarian follicles in dairy cattle: a review. Reproduction Nutrition Development 46 105-119. (doi:10.1051/rnd:2006003)

Vega Orozco A, Daneri C, Anesetti G, Cabrera R, Sosa Z \& Rastrilla AM 2012 Involvement of the oestrogenic receptors in superior mesenteric ganglion on the ovarian steroidogenesis in rat. Reproduction 143 183-193. (doi:10.1530/REP-11-0056)

Vidal S, Roman A, Moya L \& Kovacs K 2000 Expression of 3 betahydroxysteroid dehydrogenase/isomerase in the female rat pituitary. Journal of Endocrinology 166 95-101. (doi:10.1677/joe.0.1660095)

Wang L, Qiao J, Liu P \& Lian Y 2008 Effect of luteinized unruptured follicle cycles on clinical outcomes of frozen thawed embryo transfer in Chinese women. Journal of Assisted Reproduction and Genetics 25 229-233. (doi:10.1007/s10815-008-9225-2)

Williams CJ \& Erickson GF 2012 Morphology and Physiology of the Ovary. SourceEndotext [Internet]. South Dartmouth, MA, USA: MDText.com, Inc.

Westwood FR 2008 The female rat reproductive cycle: a practical histological guide to staging. Toxicologic Pathology 36 375-384. (doi:10.1177/0192623308315665)

Wolfenson D, Lew BJ, Thatcher WW, Graber Y \& Meidan R 1997 Seasonal and acute heat stress effects on steroid production by dominant follicles in cows. Animal Reproduction Science 47 9-19. (doi:10.1016/S03784320(96)01638-7)

Wolfenson D, Roth Z \& Meidan R 2000 Impaired reproduction in heatstressed cattle: basic and applied aspects. Animal Reproduction Science 60-61 535-547. (doi:10.1016/s0378-4320(00)00102-0)

Received 14 February 2016

First decision 11 March 2016

Revised manuscript received 18 October 2016

Accepted 24 October 2016 